\title{
TECHNICAL IMPROVEMENTS IN DOMINO LIVER TRANSPLANTATION
}

\author{
C. Lupaşcu ${ }^{1}{ }^{\otimes}$ J. Lerut ${ }^{2}$ \\ 1) Department of Surgery, First Surgical Unit, „St. Spiridon” Hospital Iaşi, \\ University of Medicine and Pharmacy „Gr.T. Popa” Iaşi \\ 2) Starzl Unit of Abdominal Transplantation, Cliniques Universitaires „St. Luc”, \\ Université Catholique de Louvain (UCL), Bruxelles, Belgia
}

\begin{abstract}
TECHNICAL IMPROVEMENTS IN DOMINO LIVER TRANSPLANTATION (Abstract): A new modality of liver transplantation was introduced in 1997: the sequential or domino live transplantation. In this kind of transplantation, the FAP (familial amyloidotic polyneuropathy) patients' livers are used as grafts especially for recipients older than 55-60 years. The obvious inconvenience is that the FAP liver can continue to provide transthyretin, with the probability of later development of neuropathy in the new recipient.
\end{abstract}

KEY WORDS: FAMILIAL AMYLOIDOTIC POLYNEUROPATHY;
TRANSPLANTATION

SHORT TITLE: Domino liver transplantation

HOW TO CITE: Lupaşcu C, Leut J. Technical improvements in domino liver transplantation. Jurnalul de chirurgie (Iaşi). 2013; 9(4): 357-358. DOI: 10.7438/1584-9341-9-4-9.

\section{BACKGROUND}

In patients who underwent transplantation for familial amyloidotic polyneuropathy (FAP) type I, the explanted liver is normal [1,2], except for the production of transthyretin. The original technique used for transplantation in FAP patients, has been changed to promote sequential transplantation [3].

During the hepatectomy of FAP patients, the inferior vena cava (IVC) is not preserved, and in many cases the veno venous bypass is employed $[2,4]$. Some surgeons even report that the pericardium may be sectioned in order to lengthen the vena cava stumps [2-4].

The big problem and challenge in domino liver transplantation remains the IVC length for both patients, the FAP patient and the domino recipient.
In this case, a new technical improvement may be used which allows the FAP hepatectomy to be performed with IVC preservation, in which it is not necessary to use veno - venous bypass nor to open the pericardium sac.

\section{TECHNICAL NOTE}

We report the case of a 41 years old woman who accepted to be the domino donor. A cadaveric liver graft became available and was harvested using the standard technique. The IVC bellow the renal vein, with both common iliac veins were taken to be used as vascular grafts. The FAP patient hepatectomy was performed with IVC preservation, and veno - venous bypass was not necessary. The cadaveric graft was implanted with latero-lateral venocaval anastomosis. The pedicle element 
anastomosis was performed by the standard technique. The FAP patient did not required blood transfusion. The postoperative period was completely uneventful, and the patient was allowed to leave the hospital on the $8^{\text {th }}$ postoperative day.

The FAP liver as a domino graft was harvested without vena cava, only with right, middle and left hepatic veins stumps and was perfused on the back table with Belzer solution. The middle and left hepatic veins were joined together, and the venous graft of both iliac veins with the common cuff of the IVC was anastomosed with right hepatic vein and the new common trunk of the middle and left hepatic veins, using 5-0 Pprolene ${ }^{\circledR}$ running suture.

A 63 years old man with end stage liver disease secondary to $\mathrm{C}$ hepatitis, agreed to accept the FAP liver. The recipient's liver explantation was either performed with preservation of the IVC, and the liver was implanted in the standard piggy back procedure, using the caval stump of the venous graft as the outflow from FAP liver. The postoperative course was also uneventful, and the patient was discharged on the $14^{\text {th }}$ postoperative day. The Doppler hepatic vein waveform always showed triphasic waves, consistent with a good outflow from the FAP liver.

\section{DISCUSSION AND CONCLUSION}

This new technique for domino liver transplantation was first described by Pena [1]. The vascular outflow anastomosis in the domino recipient is performed with an iliac / caval vein graft from the cadaveric donor. For this reason, some technical difficulties such as short vena cava stump, pericardial effusion, and bad outflow in both patients are avoided. This technique also avoids the required veno - venous bypass or the hemodynamic changes after caval clamping in FAP patients.

In summary, this new technical improvement may be considered as a possibility to avoid the complications described in the domino procedure, especially in the FAP patients, and are in accordance with domino transplant philosophy.

\section{CONFLICT OF INTEREST}

Authors have no conflict of interest to declare.

\section{REFERENCES}

1. Pena JR, Barroso E, Martins A. Sequential whole liver transplant resected as piggyback from FAP patients. Liver Transplant. 2002; 8: c-24

2. Azoulay D, Samuel D, Castaing D, Adam R, Said G. Domino liver transplantation for metabolic disorders: Experience with familial amyloidotic polyneuropathy. J Am Coll Surg. 1999: 189(6): 584-593.

3. Furtado A, Tomé L, Oliveira FJ, Furtado E, Viana J, Perdigoto R. Sequential liver transplantation. Transplant Proc. 1997; 29(12): 467-468.

4. Nicoluzzi JE, Massault PP, Matmar M, et al. Pitfalls of domino transplant. Transplantation. Transplantation. 2001; 72(4): 751. 